\title{
RANCANG BANGUN APLIKASI E-VOTING KETUA OSIS DI SMA PGRI 1 KOTA SERANG
}

\author{
Dadang Amiruddin ${ }^{1}$, Irma Yunita Ruhiawati ${ }^{2}$, Murnati $^{3}$ \\ ${ }^{1,2,3}$ Universitas Banten Jaya \\ Jl. Syeh Nawawi Albantani, Curug, Kota Serang, Banten \\ Email: dadang.amiruddin@gmail.com ${ }^{1}$, irmayunitaruhiawati@ unbaja.ac.id², \\ murnati133@gmail.com ${ }^{3}$
}

\begin{abstract}
The purpose of design is to develop an e-voting application for election of student council (OSIS) chairman in SMA PGRI 1 Kota Serang. The application will help optimize the process of selecting OSIS chairman through website-based e-voting so as to minimize the risk of errors in calculation of voting results due to human errors. The application design used Waterfall method so that it is easier to develop and use UML (Unified Modeling Language) for visual system modeling. This applicatio.n is developed using PHP programming language, MySQL database and CodeIgniter framework. The process of selecting OSIS chairman is carried out through the application by accessing the URL link and logging in with National Student ID Number (NISN) as the username and password, it will be given by OSIS coach at the time of election. Vote process by clicking the vote button, the number of voting votes that have been given will enter the voting results menu. If the student has already voted, the vote button will be hidden so that students cannot vote twice. This application also applies the Nä̈ve Bayes algorithm to the e-voting application of OSIS chairman, using the probability formula, which is the number of students who choose candidates divided by all students per class. The voting results are obtained from the number of votes of voters who have voted. With the e-voting application, election of OSIS chairman becomes more effective and efficient than conventional or manual voting using paper.
\end{abstract}

Keyword: codeigniter, e-voting, PHP, UML.

\section{PENDAHULUAN}

Perkembangan teknologi informasi telah memberikan dampak pada berbagai aspek kehidupan manusia, termasuk juga sektor pendidikan. Sekolah adalah tempat belajar segala hal bagi siswa, baik akademik atau non akademik. Pembelajaran akademik dibutuhkan siswa untuk dapat melanjutkan pendidikan lebih tinggi. Pembelajaran non akademik dilaksanakan untuk memberikan kesempatan kepada siswa mengembangkan bakat dan kemampuannya diluar kemampuan akademik, misalnya berorganisasi, olah raga, seni dan budaya, dan lain-lain. 
Organisasi Siswa Intra Sekolah (OSIS) adalah suatu organisasi yang berada di tingkat sekolah di Indonesia yang dimulai dari Sekolah Menengah yaitu Sekolah Menengah Pertama (SMP) dan Sekolah Menengah Atas (SMA). Seluruh siswa secara otomatis menjadi anggota OSIS. Anggota OSIS adalah seluruh siswa yang berada pada satu sekolah tempat OSIS itu berada. OSIS diurus dan dikelola oleh siswa yang terpilih untuk menjadi pengurus OSIS. Seluruh anggota OSIS berhak untuk memilih calonnya untuk kemudian menjadi pengurus OSIS. Pengurus OSIS memiliki ketua yang dipilih oleh siswa dan memiliki seorang pembina dari guru yang dipilih oleh pihak sekolah.

Pemilihan ketua OSIS dilakukan melalui pemungutan suara anggota OSIS. Suara terbanyak akan menjadi ketua OSIS terpilih. Saat ini, pemilihan ketua OSIS di SMA PGRI 1 Kota Serang dilakukan dengan cara konvensional, yaitu pemilihan kandidat ketua OSIS dilakukan di dalam kelas. Siswa memilih kandidat dengan cara maju bergantian dan menuliskan di papan tulis kandidat mana yang akan dipilih. Cara tersebut menimbulkan beberapa masalah, seperti kurang antusiasnya siswa dalam berpartisipasi melakukan pemilihan ketua OSIS, adanya kesalahan dalam perhitungan hasil pemungutan suara, dan membutuhkan waktu yang lama.

Pemungutan suara elektronik (electronic voting, e-voting) menjadi satu pilihan tepat untuk mengatasi permasalahan yang timbul dari cara pemungutan suara konvensional. Alomari (2016) menyatakan e-voting adalah pemungutan suara elektronik mengacu pada sistem apa pun di mana pemilih memberikan suaranya menggunakan sistem elektronik, bukan dengan kertas suara; e-voting dapat membantu mempercepat proses penghitungan, memberikan akses kepada masyarakat, menghemat biaya, dan meningkatkan transparansi.

Implementasi teknologi informasi melalui e-voting menghasilkan efektifitas dan efisiensi dalam pemungutan suara dibandingkan dengan menggunakan kertas seperti yang selama ini dilakukan. Merujuk pada hasil penelitian Anami dan Rachmad (2016) penggunaan e-voting dapat mengatasi permasalahan pada sistem pemungutan suara tradisional, seperti proses pemungutan suara berlangsung lebih cepat, mampu memberikan informasi hasil pemungutan suara lebih cepat dan akurat, menjamin tidak adanya suara yang 
terlewat, mencegah beberapa orang dengan pemilih yang sama, dan dapat mengurangi biaya penggunaan kertas.

Penerapan solusi e-voting pada pemilihan ketua OSIS SMA PGRI 1 Kota Serang memadukan teknologi berbasis website dengan menggunakan bahasa pemrograman PHP, basis data MySQL, algoritma Nä̈ve bayes, dan framework codeigniter yang dapat memudahkan dalam pengembangan aplikasi tersebut.

\section{METODOLOGI PENELITIAN}

\section{Metode Pengembangan Sistem}

Dalam pengembangan sebuah sistem diperlukan pendekatan atau model agar sistem yang dihasilkan dapat sesuai dengan kebutuhan. Beberapa model digunakan oleh pengembang sistem, namun model Waterfall paling banyak digunakan oleh pengembang software. Menurut Pressman (2015:42), model Waterfall melakukan pendekatan secara sistematis dan berurutan dalam beberapa tahap, yaitu:

1. Komunikasi (Communication)

Pada tahapan ini pengembang software melakukan komunikasi dengan user. Hal ini merupakan awal dari aktivitas pengembangan software. Hasil dari tahapan ini adalah informasi seperti permasalahan yang dihadapi oleh user, fungsi dan fitur sistem yang dibutuhkan.

2. Perencanaan (Planning)

Berdasarkan informasi yang diperoleh pada tahapan sebelumnya, dibuat penjadwalan (timeline) pembuatan sistem beserta perkiraan sumber daya yang dibutuhkan. Disamping itu pula bagaimana kemajuan dari proses pembuatan sistem dapat ditelusuri sehingga pembuatan sistem dapat diselesaikan sesuai dengan waktu yang telah ditetapkan.

3. Pemodelan (Modelling)

Dalam tahap ini dilakukan analisa dan perancangan sistem yang akan dibangun. Pemodelan berfokus pada perancangan struktur data, tampilan antar muka, dan algoritma program. 


\section{Konstruksi (Construction)}

Berdasarkan rancangan yang telah dibuat, langkah selanjutnya adalah melakukan pembuatan kode program (coding). Programmer akan menterjemahkan rancangan yang telah dibuat ke dalam bahasa pemrograman yang berisi perintah-perintah untuk menjalankan fungsi atau operasi tertentu. Pada tahap ini dilakuan pula testing terhadap program yang telah selesai dibuat untuk memastikan bahwa semua fungsi dan operasi pada program yang dibuat telah sesuai dengan rancangan dan tidak adanya kesalahan ketika dijalankan.

5. Penyebaran (Deployment)

Tahap ini merupakan implementasi software ke customer, pemeliharaan software secara berkala, perbaikan software, evaluasi software, dan pengembangan software berdasarkan umpan balik yang diberikan agar sistem dapat tetap berjalan dan berkembang sesuai dengan fungsinya (Pressman, 2015:17).

Pemodelan aplikasi e-voting menggunaakan Unified Modelling Language (UML). UML adalah suatu metode permodelan secara visual untuk sarana perancangan sistem berorientasi objek. UML menyediakan beberapa diagram visual yang menunjukan berbagai aspek dalam sistem. UML merupakan alat untuk mendokumentasikan analisa dan desain sistem software.

Diagram Use Case digunakan untuk menggambarkan ruang lingkup sistem yang sedang dibangun. Pada diagram Use Case terdapat Use case meliputi semua yang ada dalam sistem, dan Aktor meliputi semua yang ada di luar sistem, seperti pemakai sistem atau sistem lainnya.

\section{PEMBAHASAN}

\section{Pemodelan Aplikasi}

Dalam pengembangan aplikasi e-voting dilakukan pemodelan UML dengan menggunakan beberapa diagram, yaitu use case, aktivitas, sekuensial, dan kelas. Pemodelan dilakukan untuk memudahkan pemahaman aplikasi yang akan dibangun. 
1. Diagram Use Case

Diagram use case menggambarkan ruang lingkup aplikasi e-voting. Pada diagram use case aplikasi e-voting terdapat delapan use case dan tiga aktor, seperti terlihat pada Gambar 1.

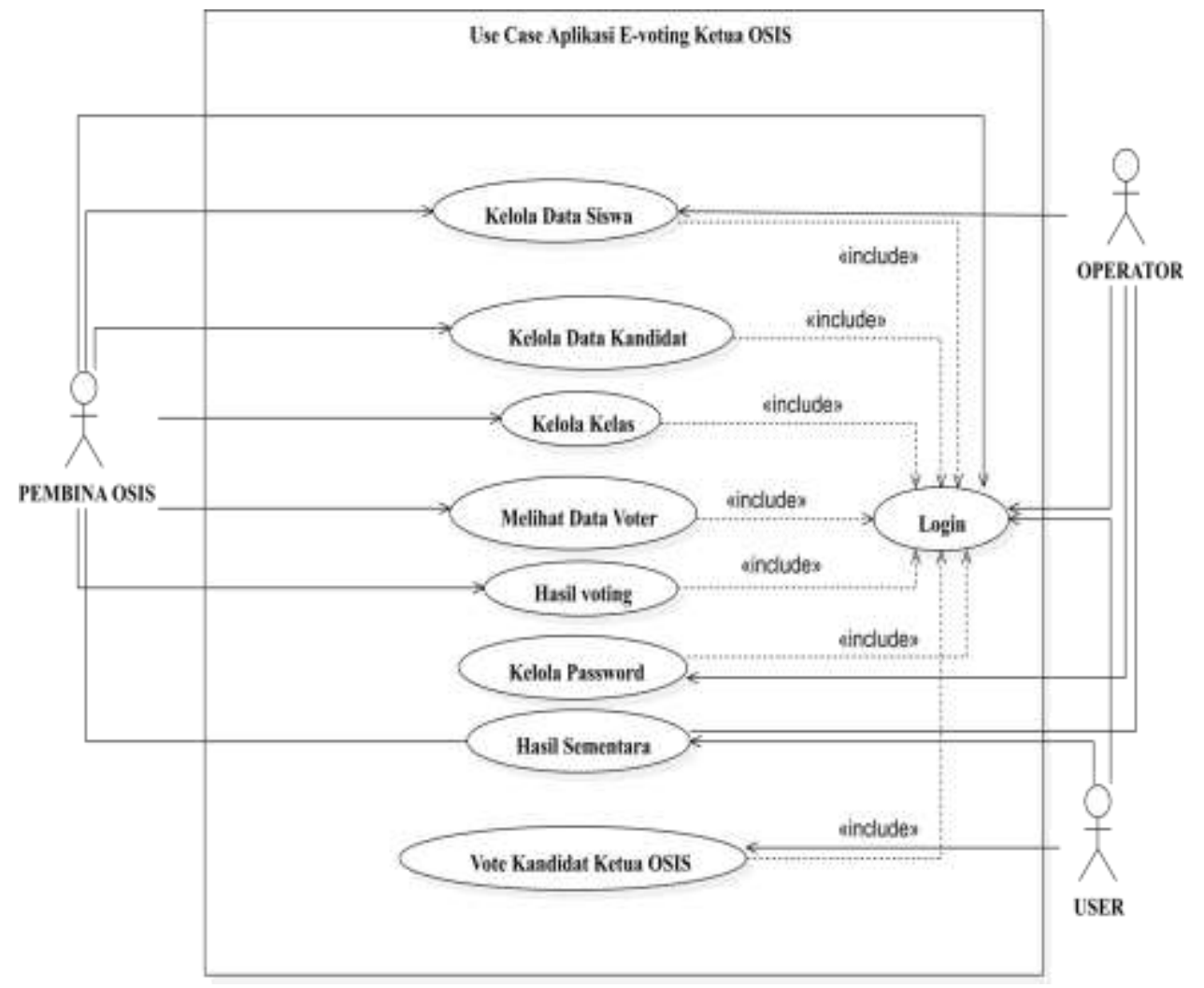

Gambar 1. Diagram use case aplikasi e-voting

2. Diagram Aktivitas

Diagram aktivitas menggambarkan aliran fungsionalitas aplikasi e-voting. Setiap siswa yang akan berpatisipasi pada pemilihan ketua OSIS SMA PGRI 1 Kota Serang harus terdaftar pada aplikasi e-voting. Oleh karenanya, pada saat siswa akan melakukan pemilihan melalui aplikasi e-voting, siswa terlebih dahulu harus melakukan login menggunakan Nomor Induk Siswa Nasional (NISN) pada aplikasi e-voting, seperti terlihat pada Gambar 2. 


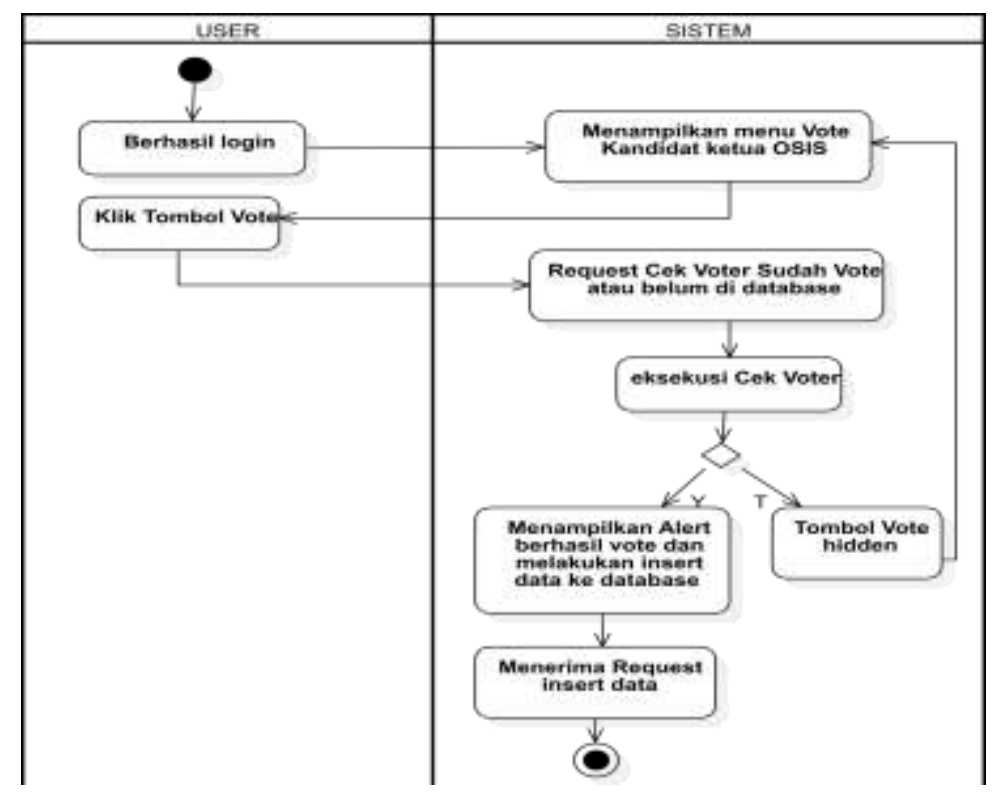

\section{Gambar 2. Diagram aktivitas pemungutan suara aplikasi e-voting}

3. Diagram Sekuensial

Diagram sekuensial menggambarkan interaksi antar objek di dalam dan di sekitar aplikasi e-voting (termasuk pengguna, display/form) berupa message yang digambarkan terhadap waktu. Diagram sekuensial menggambarkan proses pemungutan suara oleh siswa dan hasil perhitungan suara pemilihan ketua OSIS SMA PGRI 1 Kota Serang dan dengan menggunakan aplikasi evoting, seperti terlihat pada Gambar 3 dan Gambar 4.

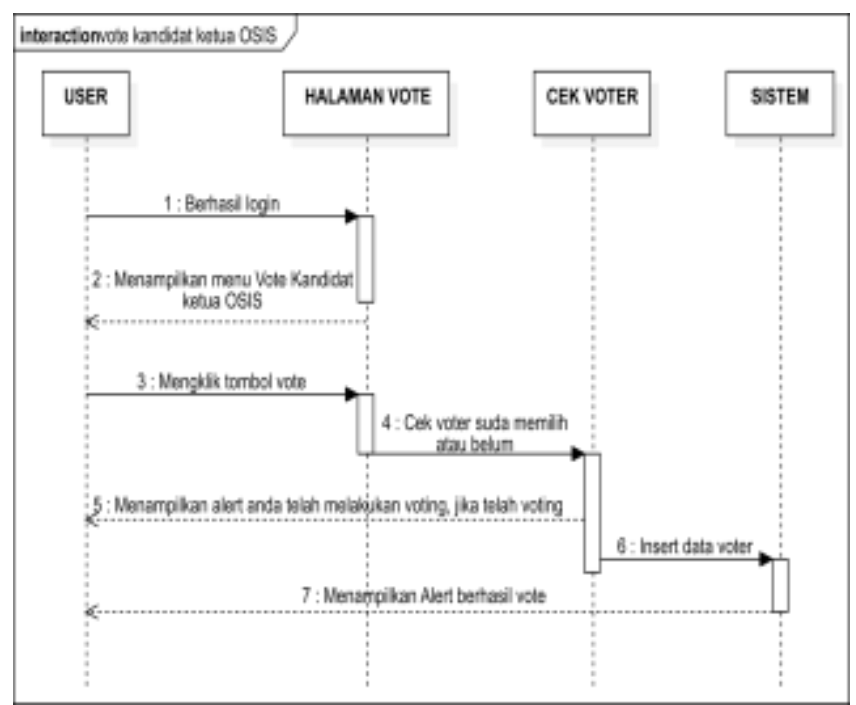

Gambar 3. Diagram sekuensial proses pemungutan suara aplikasi e-voting 


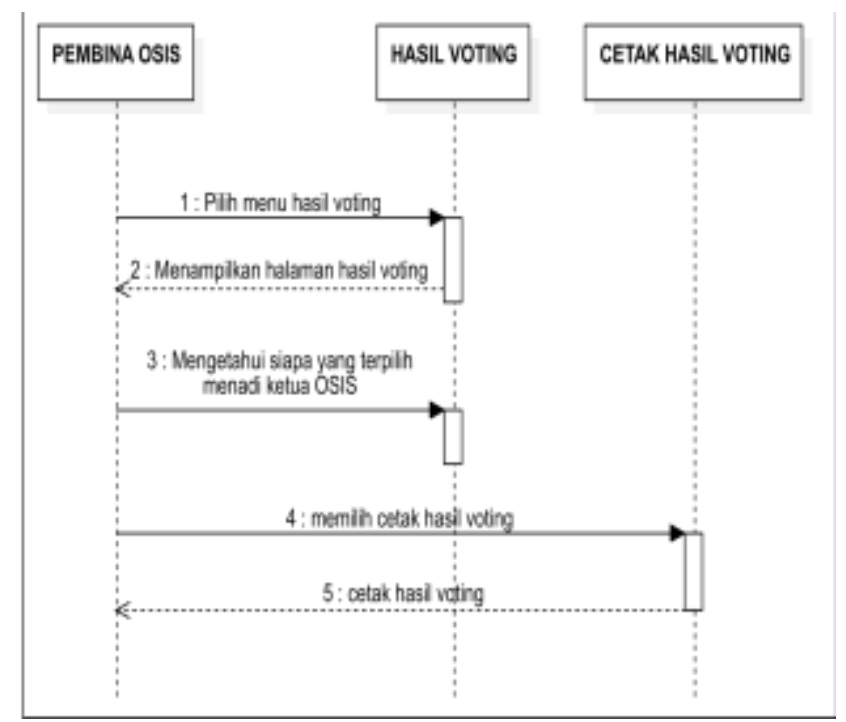

Gambar 4. Diagram sekuensial perhitungan suara aplikasi e-voting

4. Diagram Kelas

Diagram Kelas adalah model statis yang menggambarkan struktur dan deskripsi kelas serta hubungannya antara kelas di dalam aplikasi e-voting. Aplikasi e-voting memiliki 7 kelas, seperti terlihat pada Gambar 5.

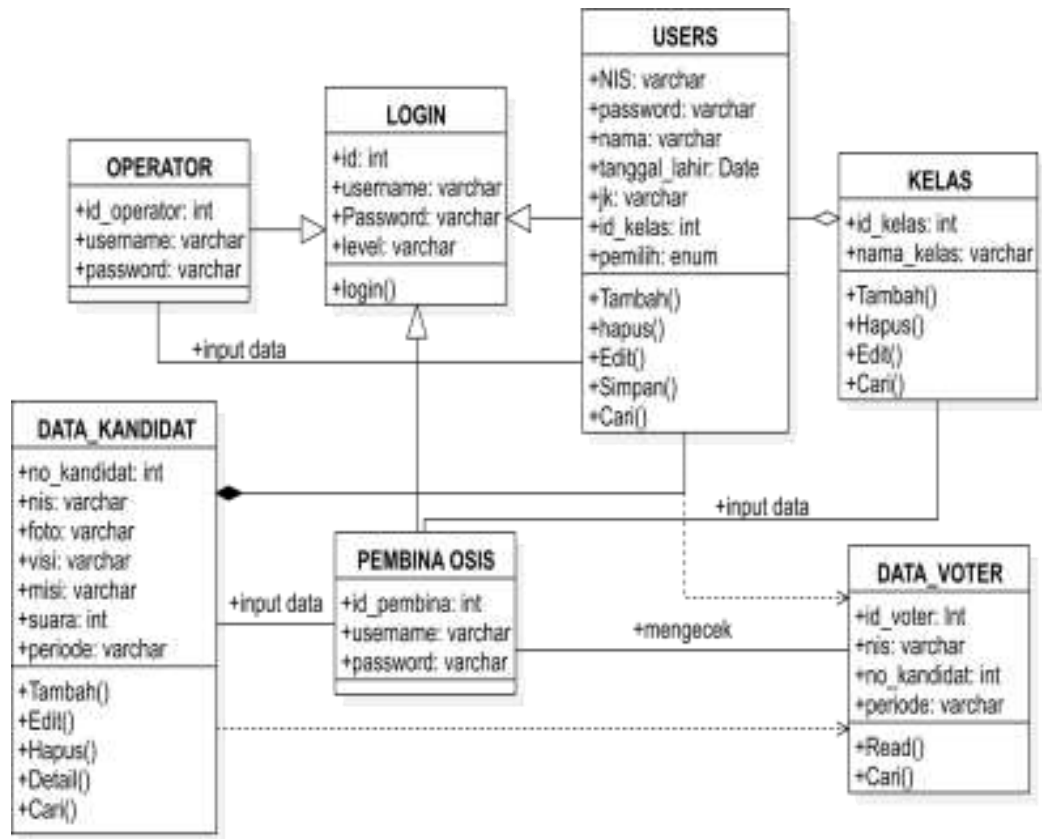

Gambar 5. Diagram kelas aplikasi e-voting 


\section{Implementasi Aplikasi e-Voting}

Aplikasi e-voting terinstal pada server dan dapat diakses melalui jaringan internet oleh setiap siswa yang telah terdaftar sebagai pemilih, seperti terlihat pada Gambar 6.

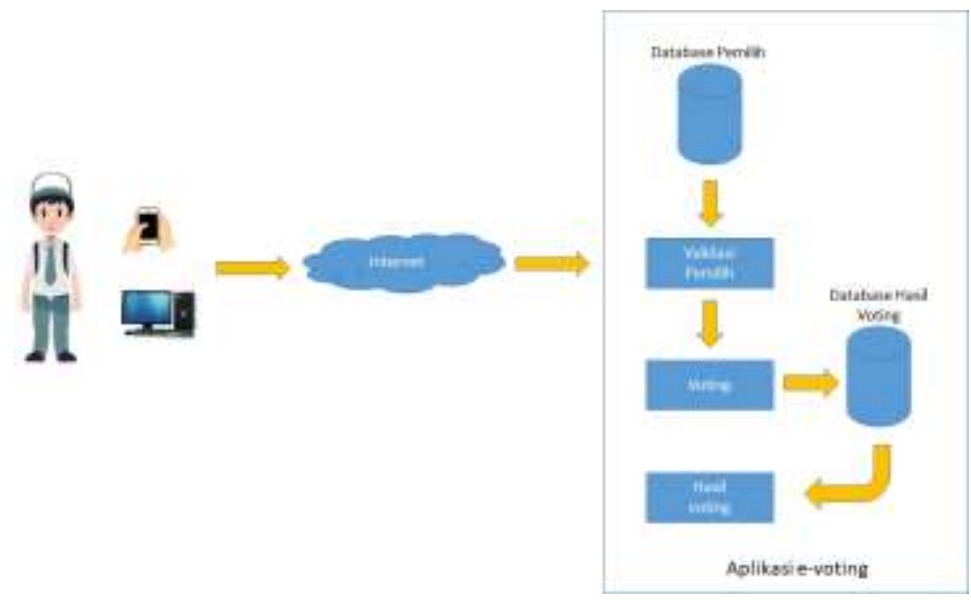

Gambar 6. Arsitektur Aplikasi e-voting

Aplikasi e-voting ini memiliki beberapa keunggulan, antara lain, meniadakan penggunaan kertas pada saat proses pemungutan suara dilakukan, karena proses pemungutan dan perhitungan suara dilakukan secara elektronik dan tersimpan dalam database, sehingga hal ini dapat mengurangi biaya untuk pengadaan kertas pemungutan suara; aplikasi e-voting mampu mencegah terjadinya seorang pemilih melakukan pemberian suara lebih dari satu kali; hasil perhitungan suara dapat dilihat secara realtime selama proses sampai dengan pemungutan suara selesai dilakukan.

Setiap siswa yang akan memberikan suaranya, harus melakukan login dengan menggunakan NISN masing-masing. Aplikasi e-voting akan melakukan pengecekan status pemilih dari setiap siswa yang login. Jika status pemilih adalah "N", maka dapat melanjutkan proses pemilihan kandidat ketua OSIS SMA PGRI 1 Kota Serang, namun jika status pemilih adalah "Y", maka siswa tidak masuk ke dalam aplikasi e-voting. Proses login siswa seperti terlihat pada Gambar 7. 


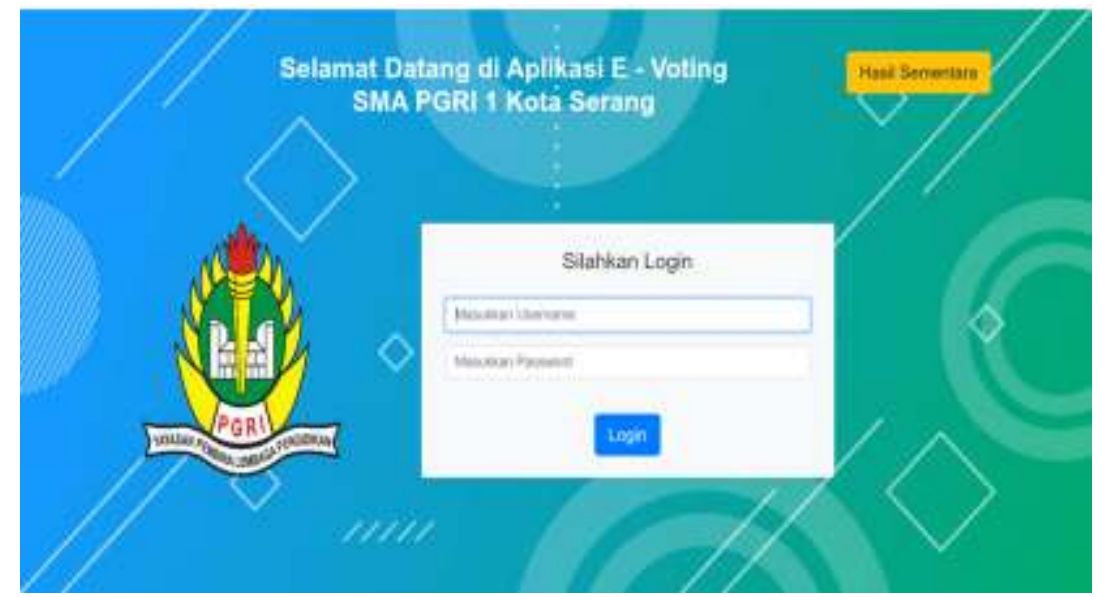

Gambar 7. Menu Login aplikasi e-voting

Untuk menghindari terjadinya seorang siswa melakukan pemilihan atau pemungutan suara lebih dari satu kali, maka pada tabel master user (siswa) dibuat field yang menunjukan status dari pemilih (siswa), apakah sudah memberikan suaranya atau belum. Untuk itu, data setiap siswa akan diberi nilai awal status "N" yang artinya belum memilih, dan ketika siswa sudah memberikan suaranya, maka status pemilih akan berubah menjadi "Y" yang artinya sudah memilih atau memberikan suaranya.

Setelah siswa berhasil login ke dalam aplikasi e-voting, akan ditampilkan informasi kandidat ketua OSIS SMA PGRI 1 Kota Serang yang dapat dipilih. Informasi kandidat terdiri dari photo, nama kandidat, visi, dan misi. Untuk memilih kandidat, siswa dapat menekan tombol "vote" dibawah photo kandidat, seperti terlihat pada Gambar 8 .

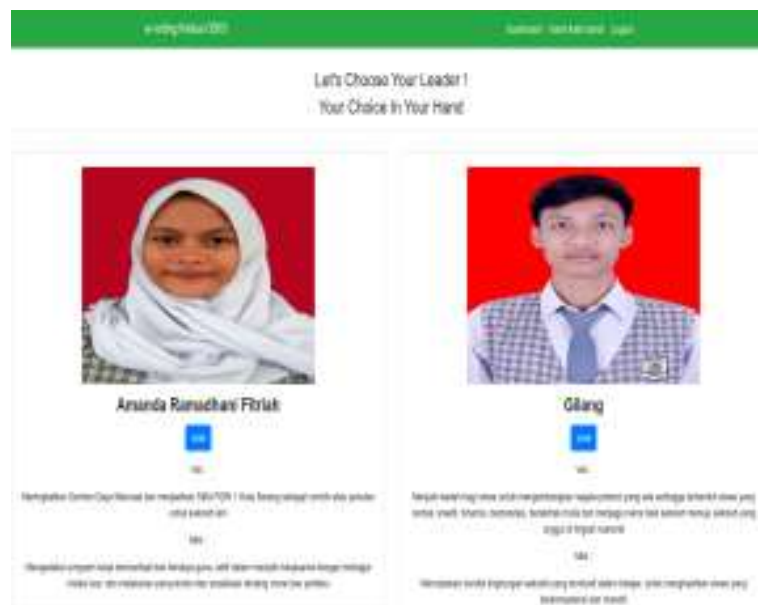

Gambar 8. Menu pemilihan ketua OSIS aplikasi e-voting 
Hasil pemungutan suara sementara dapat dilihat secara real time setiap waktu sesuai dengan jumlah suara yang masuk ke dalam aplikasi e-voting, seperti terlihat pada Gambar 9.

\section{E-voting Ketua OSIS SMA PGRI 1 Kota Serang}

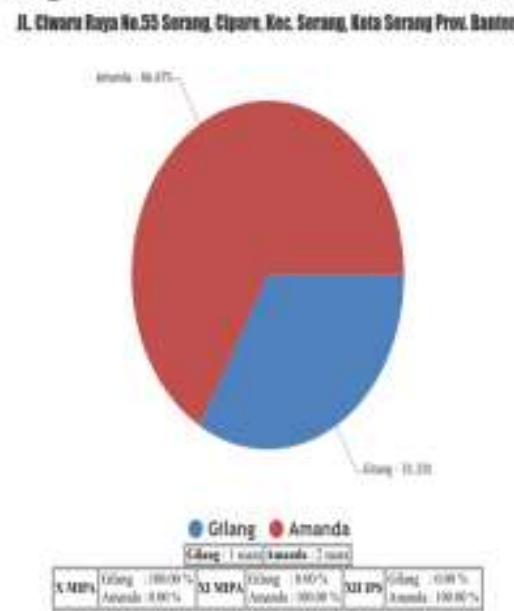

\section{Gambar 9. Menu hasil sementara pemungutan suara aplikasi e-voting}

Ketika proses pemungutan suara telah selesai, maka akan langsung didapatkan hasil perhitungan akhir suara dan menentukan kandidat yang memperoleh suara terbanyak dan terpilih menjadi ketua OSIS SMA PGRI 1 Kota Serang, seperti terlihat pada Gambar 10.

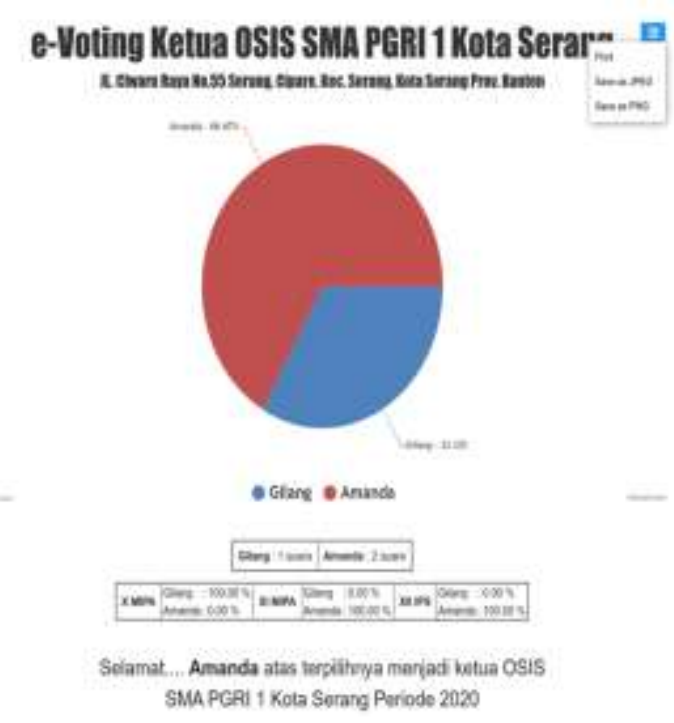

Gambar 10. Menu hasil akhir pemungutan suara aplikasi e-voting 


\section{KESIMPULAN}

Penerapan pemungutan suara secara elektronik (e-voting) memiliki beberapa kelebihan dibandingkan dengan pemungutan suara secara konvesional dengan menggunakan kertas, antara lain:

1. Kesalahan dalam perhitungan suara dapat dihindari, karena dilakukan oleh aplikasi dan tidak ada intervensi dari manusia.

2. Proses perhitungan suara lebih cepat, transparan, dan dapat dipercaya karena dilakukan oleh aplikasi dan tidak dapat diintervensi oleh manusia.

3. Hasil perhitungan suara sementara dan akhir dapat diperoleh dengan cepat dan real time.

4. Dengan beberapa kelebihan di atas, aplikasi e-voting dapat dikembangkan lebih lanjut untuk kepentingan yang lebih besar lagi, misalnya pemungutan suara untuk pemilihan anggota Legislatif, Bupati, Walikota, Gubernur, atau Presiden.

\section{DAFTAR PUSTAKA}

Anamisa, D. R., \& Rachmad, A. (2016). THE ELECTION KLEBUN BASED PPLICATION. International Journal of Advanced Research in Computer Engineering \& Technology (IJARCET), 5(4).

Arief, M. Rudyanto. (2011). Pemrograman Web Dinamis Menggunakan PHP dan MYSQL. Yogyakarta: Andi Offset

Asyikin, Arifin Noor, (2019). Pemrograman Web. Yogyakarta: Deepublish

A.S, Rosa dan M. Shalahuddin, (2015). Rekayasa Perangkat Lunak - Terstruktur dan Berorientasi Objek. Bandung: Informatika

Hendrawan, J., Perwitasari, I. D., \& Senjani, D. (2019). Aplikasi Pemilihan Ketua OSIS Berbasis Android pada SMP Budi Utomo Medan. x.

Ikhsan dkk., (2014). Memahami E-voting: Berkaca dari Pengalaman Negaranegara Lain dan Jembrana. Jakarta: Yayasan Pustaka Obor Indonesi

Jubilee Enterprise, (2015). Mengenal Java dan Database dengan Netbeans. Jakarta: PT. Alex media komputindo

Kusini dkk, (2009), Algoritma data mining. Yogyakarta: Andi Offset

Nisa, Khairun. Adnan, Fachri. (2019). Implementasi Elektronik Voting (E-Voting) Dalam Pemilihan Walinagari Di Nagari Salareh Aia Kabupaten Agam Tahun 2017. Journal of Residu, 53(9), 1689- 
1699.https://doi.org/10.1017/CBO9781107415324.004 diakses pada tanggal $\underline{10 \text { april } 2020}$

Nugroho, Bunafit, (2013). Dasar Pemograman Web PHP - MySQL dengan Dreamweaver. Yogyakarta: Gava Media

Oliver, J. (2015). Aplikasi Pendaftaran dan Pemilihan Pengurus OSIS SMK Sudirman 1 Wonogiri Berbasis Website Journal of Chemical Information and Modeling, 53(9), 1689-1699. https://doi.org/10.1017/CBO9781107415324.004 diakses pada tanggal 10 april 2020

Pressman, R.S. (2015) Rekayasa Perangkat Lunak: Pendekatan Praktis Buku I. Yogyakarta: Andi.

Ramadhani, (2019), Pemrograman Dasar Java Visual Berbasis Database MYSQL. Yogyakarta: Deepublish

Repository. (2019). No Title. Repository.Bsi.Ac.Id. https://repository.bsi.ac.id/index.php/unduh/item/1630/File_10-Bab-IILandasan-Teori.pdf diakses pada tanggal 10 april 2020

Solichin, Achmad, (2016). Pemrograman Web dengan PHP dan MySQL. Jakarta: Budi luhur

Sri Mulyani, (2016). Metode analisis dan perancangan sistem. Bandung: Abdi Sistematika

Suntoro, Joko, (2019), Data Mining: Algoritma dan Implementasi dengan pemrograman PHP. Jakarta: Elex Media Komputindo

Supono, (2018). Pemrograman web dengan menggunakan PHP dan Framework CodeIgniter. Yogyakarta: Deepublish

Touseef, M, Anwer., et al., (2015). Testing from UML Design using Activity Diagram: A Comparison of Techn iques. International Journal of Computer Applications, 05/2015, Vol 131, hal. 41.

Widianto, Mochammad Haldi. (2019), “Algoritma Naïve Bayes”, https://binus.ac.id/bandung/2019/12/algoritma-naive-bayes/, diakses pada tanggal 08 april 2020 